Macedonian Pharmaceutical Bulletin, 66 (Suppl 1) 193 - 194 (2020)

Online ISSN 1857 - 8969

UDC: $615.2: 339.188 .2$

DOI: 10.33320/maced.pharm.bull.2020.66.03.096

Short communication

\title{
Good Distribution Practice in preserving the integrity and safety of the supply chain of pharmaceuticals
}

\author{
Filip Cvetanovski ${ }^{1}{ }^{*}$, Nikola Kocev ${ }^{1}$, Jasmina Tonic-Ribarska ${ }^{2}$, \\ Suzana Trajkovic-Jolevska ${ }^{2}$ \\ ${ }^{1}$ Alkaloid AD Skopje, Blvd. Aleksandar Makedonski, 12, 1000, Skopje, Republic of North Macedonia \\ ${ }^{2}$ Faculty of Pharmacy, UKIM, Mother Teresa Str., 47, 1000 Skopje, Republic of North Macedonia
}

\section{Introduction}

The Good Distribution Practice (GDP) represents a collection of standardized, routine methods of work, which ensure that the characteristics defining the quality, safety and efficacy of the pharmaceutical products remain intact from the beginning to the end of their stay in the pharmaceutical supply chain, (European Commission, 2013). According to these practices, the pharmaceutical products should be stored according to the prescribed storage conditions, especially during the process of transportation. Since the manufacturers of the pharmaceutical products that also distribute their assortment are inspected and authorized in the Good Manufacturing Practice (GMP), they are exempted from the obligation of acquiring separate authorization for distribution. Every other legal entity has to be authorized to do so. The principles laid in the GDP expand outside of the pharmaceutical products' distribution and include the procurement, storage and transport of active substances and other ingredients used in the manufacturing process. The global pharmaceutical chain is an immensely complicated organization.

However, its all-encompassing nature can either provide many opportunities for greater efficiency or render it susceptible for emergence of weak points that can ease the entrance of illicit products.
Probably the greatest risk for the legal distribution chain are the falsified pharmaceutical products.

These products pose a threat for the general well-being, health and the life of the unfortunate patients that are exposed to them. There are estimations that one tenth of the pharmaceutical supply chain in the developing countries consists of falsified medicines (WHO, 2018).

\section{Good Distribution Practice}

Protecting the distribution chain encompasses several important points. Firstly, it is important to draw up maps according to which the distribution shall be completed (introduction to the routes and the conditions of the transportation process).

According to this information, an assessment of the risks should be made. The products' and the distribution chain's control is dependent on the risk analysis, which is a constantly changing subject, due to the non-stop control and monitoring of the products' safety (Ulrich, 2017). It can generally be considered that the pharmaceutical products coming directly from the production site to the pharmacy or the authority dispensing them to the patients are legitimate and not falsified. The risks of falsified products entering the supply chain emerge when the product changes distributors several times.

\footnotetext{
*fcvetanovski@alkaloid.com.mk
} 
Additionally, many products are re-packed, relabelled etc. Even their storage can be inconsistent in terms of location. Another problem is posed by the reverse-distribution (returned products). In all these points, the products can be stolen, altered and changed, which not only damages the companies financially, but also is a major public health threat (IOM, 2013). Essentially the protection of the supply chain can be facilitated by following the rules and propositions laid out in the regional guidelines on the matter, such as the Guideline on GDP of 2013 issued by the European Commission, the WHO Guideline on Good Storage and Distribution Practices (WHO, 2019) and the USP chapter 1079 on Good Storage and Distribution Practices for Drug Products (USP, 2019). These guidelines propose several points of consideration such as the importance of implementing an all-encompassing, comprehensive quality management system, that should be drawn up as a set of interactive elements based on procedures, rules, resources and goals that are collectively established with the mission of running an organization. The obligation that the procurement, distribution, storage and transportation should be done with the characteristics laid out in the GDP; the clear definition of the management's and other personnel's roles and responsibilities, the practice of documenting every activity, recording and investigating every deviation from the defined procedures, are considered as the essential requirements that a fully functioning quality management system should be able to perform. Such system has to be built around the ability to correctly assess and predict risks, i.e. operating around an appropriate risk-management system (ICH, 2005).

The main postulates for managing the risks are basing the evaluation of the risks to the quality on scientific knowledge, levelling the effort, formality and documentation of the processes in equivalence with the risks and ultimately focusing on the patients. Proper and responsible management of the personnel of the company, the activities of the responsible person and the trainings should encompass every activity done within the company.

The premises and equipment must be suitable and adequate to ensure proper storage and distribution of medicinal products. The document management, the definition of the different operations (qualification of suppliers and customers, receiving products, storage etc.) should ensure that the identity of the medicinal products is not lost and that the distribution is performed according to the information on the outer packaging. The complaints, returned and recalled products, the treatment of falsified medicines, outsourced activities, selfinspections and the provisions for the brokers are points of consideration.

\section{Conclusions}

The patients' health is undoubtedly a priority for the pharmaceutical industry. That being said the good distributional practices and their proper implementation have an immense role in sustaining the quality, safety and efficacy of the distributed pharmaceutical products by preventing incidents such as falsifying, theft, manipulation, illicit transfer and the temperature excursions - changes in the temperature during transportation.

These rules secure that the right pharmaceutical product will reach the right recipient at the right time in the right condition.

\section{References}

European Commission, 2013. Guidelines of 5 November 2013 on Good Distribution Practice of medicinal products for human use. Official Journal of the European Union. C 343, 1-14.

International conference on harmonization of technical Requirements for registration of pharmaceuticals for human use (ICH), 2005. Q9, Pharmaceutical Risk Management. Harmonized tripartite guideline.

European Medicines Agency (EMA), 2015. ICH guideline Q9 on quality risk management. Committee for Human Medicinal Products.

IOM (Institute of Medicine), 2013. Countering the problem of falsified and substandard drugs. The National Academies Press.

The United States Pharmacopeia (USP) Convention, 2019. The United States Pharmacopeia and National Formulary (USP 42-NF 37), chapter 〈1079〉 Good Storage and Distribution Practices for Drug Products. Rockville, MD, USA.

Ulrich, D., 2017. Global GDP's - A Risk Based Approach to Management of Distribution. USP-APEC RHSC.

World Health Organization (WHO), 2018. Substandard and falsified medical products. Available at: https://www.who.int/news-room/fact-sheets/detail/ substandard-and-falsified-medical-products (Last accessed on 01.03.2020).

World Health Organization (WHO), 2019. Good Storage and Distribution Practices. QAS/19.793/Rev.1.

Maced. Pharm. Bull. 66 (Suppl 1) 193 - 194 (2020) 